\title{
Synergistic inhibitory effects of low-dose decitabine in combination with bortezomib in the AML cell line Kasumi-1
}

\author{
VASSILIKI MPAKOU $^{1}$, ARIS SPATHIS ${ }^{2}$, ANTHI BOUHLA ${ }^{1}$, EFTHIMIA MPAZANI ${ }^{1}$, \\ SOTIRIOS PAPAGEORGIOU ${ }^{1}$, KONSTANTINOS GKONTOPOULOS ${ }^{1}$, EIRINI GLEZOU ${ }^{1}$, \\ THOMAS THOMOPOULOS ${ }^{1}$, PERIKLIS FOUKAS ${ }^{2}$ and VASILIKI PAPPA ${ }^{1}$ \\ ${ }^{1}$ Second Department of Internal Medicine and Research Institute; ${ }^{2}$ Second Department of Pathology, \\ National and Kapodistrian University of Athens, Attikon University General Hospital, Athens 12462, Greece
}

Received January 20, 2020; Accepted November 17, 2020

DOI: $10.3892 / \mathrm{etm} .2021 .9628$

\begin{abstract}
In the present study, the ability of the proteasome inhibitor bortezomib (BZ), an oxidative stress-inducing agent, to sensitize acute myeloid leukemia (AML) cells to decitabine (Dacogen ${ }^{\circledR}$, DAC; a DNA methyltransferase inhibitor), in terms of cell viability and differentiation, was investigated. Kasumi-1 AML (M2) cells were treated with low-dose DAC $(10,50,100,200$ or $400 \mathrm{nM})$, with or without BZ (10 nM). Apoptosis and the cell cycle were evaluated after $24 \mathrm{~h}$ of treatment through fluorescence-assisted cell sorting (FACS) with Annexin V/propidium iodide and DAPI staining, respectively. The expression levels of CD193, CD11b, CD13, CD14, CD15, CD16 and CD117 surface differentiation markers were evaluated by FACS after 6 days of treatment. The results indicated significant alterations in cell death and cell cycle phases in Kasumi-1 cells following DAC and BZ combination treatment compared to untreated cells and cells with single treatments. Low-dose DAC/BZ combinations significantly enhanced apoptosis and decreased the population of live Kasumi-1 cells, with 100 and $200 \mathrm{nM}$ of DAC and $10 \mathrm{nM} \mathrm{BZ}$ appearing to have the most potent synergistic effect according to a combination index. Furthermore, cell cycle profiling revealed that $\mathrm{DAC} / \mathrm{BZ}$ treatment synergistically led to G0/G1- and G2/M-phase arrest. By contrast, DAC appeared to promote monocytic and granulocytic differentiation of Kasumi-1 cells more effectively alone than in combination with BZ. BZ acted synergistically with low-dose DAC in vitro, leading to enhanced apoptosis and G0/G1- and G2/M-phase arrest in AML cells, hence prohibiting either DNA synthesis or mitosis. Although further in vivo investigation is necessary,
\end{abstract}

Correspondence to: Professor Vasiliki Pappa, Second Department of Internal Medicine and Research Institute, National and Kapodistrian University of Athens, Attikon University General Hospital, 1 Rimini Street, Haidari, Athens 12462, Greece

E-mail: vas_pappa@yahoo.com

Key words: acute myeloid leukemia, Kasumi-1, decitabine, bortezomib these results provide a strong rationale for the implementation of a combination treatment with DAC and bortezomib in AML therapy, followed by DAC alone, which may achieve better clinical responses and possibly partially overcome the frequently encountered DAC resistance of patients with AML.

\section{Introduction}

Acute myeloid leukemia (AML) is a heterogeneous clonal hematopoietic neoplasm characterized by maturation arrest in the myeloid lineage. AML accounts for $70 \%$ of all cases of acute leukemia (1) and it is thought to be propagated by a subpopulation of leukemia stem cells (LSCs) with the ability to self-renew, an unlimited repopulating potential and residence in a quiescent state in G0/G1 phase (2-6). The standard of care regimen for AML has remained almost the same over the last 40 years, with only slight amendments, and consists of an anthracycline and cytarabine combination, followed by consolidation therapy $(7,8)$. However, current treatments do not lead to long-term complete remission. Relapse remains a major hurdle for successful AML chemotherapy (9), and thus, the discovery of effective alternative AML treatment strategies is a priority.

Aberrant epigenetic modifications, including DNA and histone methylation, as well as histone acetylation, are key contributors to leukemia initiation and maintenance (6). Epigenome-modifying drugs, including decitabine (Dacogen ${ }^{\circledR}$, DAC; chemical name, 5-aza-2'-deoxycytidine), have shown promise as single therapeutic agents for AML at low doses, while higher doses are associated with cellular differentiation and cytotoxicity (10-12). DAC is a DNA methyltransferase inhibitor (DNMTi) leading to DNA hypomethylation, gene activation, cell differentiation and apoptosis $(13,14)$, and is approved by the US Food and Drug Administration for the treatment of myelodysplastic syndrome (MDS) and AML.

Oxidative stress inducers comprise another class of drugs that has been strongly implicated in the targeting of LSCs, since increased oxidation is associated with reduced self-renewal, which in turn leads to either differentiation or death of haemopoietic cells. However, induction of oxidative stress alone is not sufficient for AML treatment. Bortezomib (BZ) is a proteasome inhibitor approved for the treatment 
of multiple myeloma and mantle cell lymphoma with the ability to induce oxidative stress $(15,16)$. In AML, BZ lacks activity as a single agent (17) but produces promising results when used in combination regimens (with idarubicin and cytarabine) (18). Of note, in AML, BZ is also considered as an indirect transcriptional inhibitor, since it appears to disrupt the interactions among microRNA (miR)-29b, the transcription factor signaling protein 1 (SP1) and NF- $\mathrm{kB}(\mathrm{p} 65)$, affecting the expression of several genes in myeloid leukemia cells, including DNMTs and the receptor tyrosine kinase KIT $(19,20)$. Activating KIT mutations, which are frequently observed in core-binding factor (CBF) AML, have been indicated to induce MYC-dependent miR-29b repression, which results in increased levels of SP1 (a miR-29b target), leading to NF- $\kappa \mathrm{B}(\mathrm{p} 65)$-mediated KIT transactivation and induction of its own transcription via miR-29b. BZ targets the miR-29b/SP1/NF- $\kappa \mathrm{B}(\mathrm{p} 65)$ complex-dependent KIT overexpression and therefore manages to inhibit the growth of leukemic cells via upregulation of miR-29b (19).

While only $\sim 50 \%$ of patients treated with DNMTis have a haematological improvement (HI) or better, few alternative treatments exist for patients who fail to respond. Therefore, we investigated the possible sensitization of AML cells to DAC, through its combination with an oxidative stress-inducing agent, namely the proteasome inhibitor BZ.

\section{Materials and methods}

Cell culture. The human CBF AML Kasumi-1 cell line, carrying the $t(8 ; 21)$ and the KIT mutation N822 was purchased from the German Collection of Microorganisms and Cell Cultures $\mathrm{GmbH}$ (Leibniz Institute). Cells were cultured in RPMI-1640 (Gibco; Thermo Fisher Scientific, Inc.), supplemented with $20 \%$ fetal bovine serum (FBS; Gibco; Thermo Fischer Scientific, Inc.), $100 \mu \mathrm{g} / \mathrm{ml}$ penicillin (Invitrogen; Thermo Fischer Scientific, Inc.) and $100 \mu \mathrm{g} / \mathrm{ml}$ streptomycin (Invitrogen; Thermo Fischer Scientific, Inc.) in $5 \% \mathrm{CO}_{2}$ at $37^{\circ} \mathrm{C}$. The cells were passaged at a ratio of $1: 4$ every 4 days.

Drug treatment. For drug treatment, Kasumi-1 cells were cultured as above and treated with low doses of DAC $(10,50$, 100, 200 and $400 \mathrm{nM}),(21), \mathrm{BZ}(10 \mathrm{nM})(22)$, or their combination, at $37^{\circ} \mathrm{C}$ in a humidified atmosphere with $5 \%$ $\mathrm{CO}_{2}$, for $24 \mathrm{~h}$ for cell apoptosis and cell cycle profiling and for 6 days for immunophenotype analysis.

Flow cytometric analysis of cell apoptosis. Kasumi-1 cells were plated in 6 -well-plates $\left(5 \times 10^{5}\right.$ cells/well $)$ and treated with different concentrations of DAC and/or BZ, as described above, for $24 \mathrm{~h}$. Apoptosis was estimated through Annexin V/propidium iodide staining (Biolegend) according to the manufacturer's protocol. Flow cytometric analysis was performed using a CyFlow ML (Partec).

Cell cycle profiling. Kasumi-1 cells were plated in 6-well-plates $\left(5 \times 10^{5}\right.$ cells/well) and treated with the indicated concentrations of DAC and/or BZ for $24 \mathrm{~h}$, harvested, washed in PBS and fixed in ice-cold methanol for $10 \mathrm{~min}$. Cells were then washed in PBS and stained with $1 \mu \mathrm{g} / \mathrm{ml}$ of DAPI in PBS for $15 \mathrm{~min}$ at room temperature. The cell-cycle distribution was analyzed on a CyFlow ML (Partec) equipped with a violet laser.

The synergistic effect between low doses of DAC and BZ was evaluated by determining the combination index (CI) based on the Chou-Talalay method (23). The CI value was calculated using the following equation: $\mathrm{CI}=(\%$ decrease of viable cell number by compound $\mathrm{A}+\%$ decrease of viable cell number by compound $\mathrm{B}) /(\%$ decrease of viable cell number by combination of compound A and B). The combination effect was defined as 'synergistic', 'additive' or 'antagonistic' when CI was $<1,1$ or $>1$, respectively $(24,25)$.

Immunophenotypic characterization. Kasumi-1 cells were plated in 6-well-plates $\left(5 \times 10^{5}\right.$ cells/well) and treated for 6 days with the indicated concentrations of DAC and/or BZ. DAC and/or BZ were administrated fresh every $24 \mathrm{~h}$, along with fresh medium. Untreated cells were plated at a density of $3 \times 10^{5}$ cells/well. After washing and blocking with FcBlocker (cat. no. 422302; BioLegend, Inc.) for $10 \mathrm{~min}$ at room temperature, cells were stained in three 4-color tubes with FITC-conjugated anti-CD11b (cat. no. 301329; BioLegend, Inc.), anti-CD14 (cat. no. CYT-14F6; Cytognos), anti-CD15 (cat. no. CYT-15F4; Cytognos), phycoerythrin (PE)-Cyanine 5-conjugated anti-CD16 (cat. no. 302010; BioLegend, Inc.) and anti-HLA-DR (cat. no. 307608; BioLegend, Inc.), allophycocyanin-conjugated anti-CD45 (cat. no. CYT-45AP5; Cytognos) and PE-conjugated anti-CD13 (cat. no. 301704; BioLegend, Inc.), anti-CD117 (cat. no. 313204; BioLegend, Inc.) and anti-CD193 (cat. no. 310706; BioLegend, Inc.). The analysis was performed on a CyFlow ML (Partec).

Statistical analysis. Statistical analyses were performed with SPSS software (version 25.0; IBM Corp.). All experiments were performed three times and values are expressed as the mean mean \pm standard deviation. One-way analysis of variance followed by the least-significant differences/Bonferroni's multiple-comparison tests were used to compare the means among more than two different groups. A two-sided $\mathrm{P}<0.05$ was considered to indicate statistical significance.

\section{Results}

$B Z$ synergizes the apoptotic effect of low-dose DAC on Kasumi-1 cells. Initially, the possible synergistic effect of BZ on DAC in the induction of apoptosis in AML (M2) Kasumi-1 cells was assessed.

Single-agent treatment of Kasumi- 1 cells with various concentrations of low-dose DAC $(10,50,100,200$ or $400 \mathrm{nM})$ or BZ (10 nM) for $24 \mathrm{~h}$ resulted in a statistically significant increase in the proportion of apoptotic cells from $15.15 \pm 0.21 \%$ in the untreated cells to $27.2 \pm 7.91$ and $28.25 \pm 0.77 \%$ after treatment with 100 and $400 \mathrm{nM}$ of $\mathrm{DAC}(\mathrm{P}=0.037$ and $\mathrm{P}=0.026$, respectively) and $30.5 \pm 3.39 \%$ following treatment with $10 \mathrm{nM}$ $\mathrm{BZ}$ ( $\mathrm{P}=0.011$; Fig. 1).

When Kasumi-1 cells were subjected to DAC/BZ combination treatment, increased apoptotic rates compared to untreated cells were observed for all DAC/BZ combinations tested, with a higher apoptotic ratio observed after treatments with 100 or $400 \mathrm{nM}$ of DAC with BZ $(54.65 \pm 1.9$ and $55.55 \pm 11.8 \%$ of apoptotic cells, respectively; $\mathrm{P}<0.001$ ). 

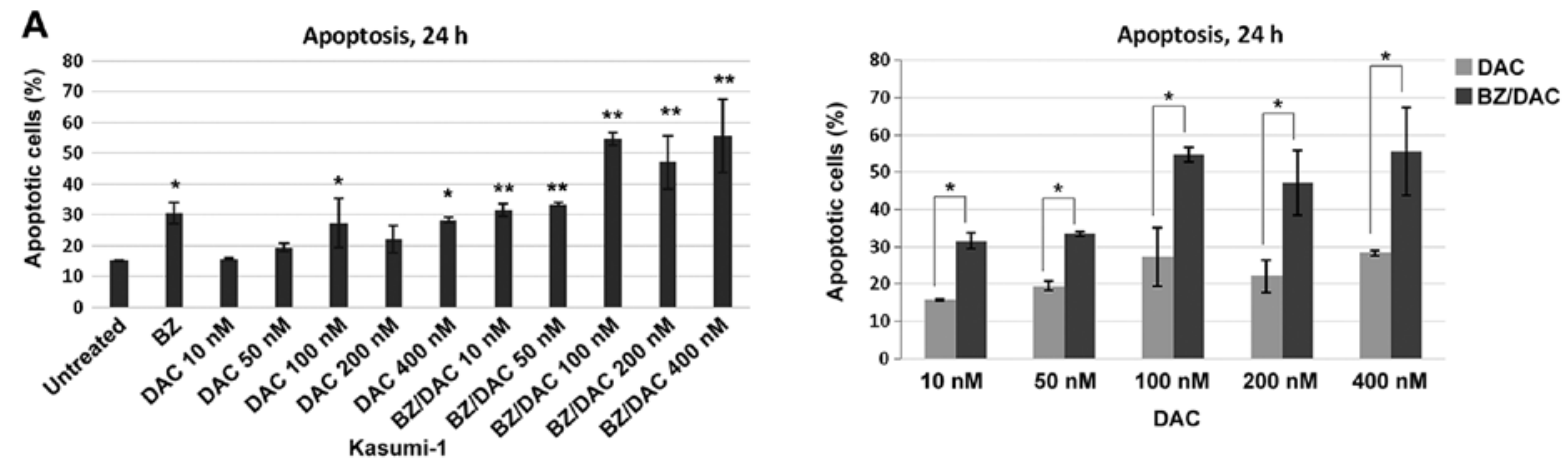

B
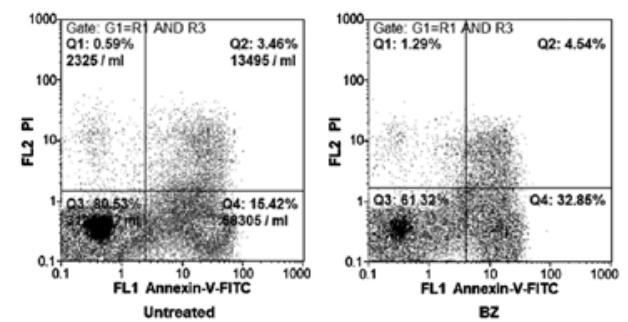

C

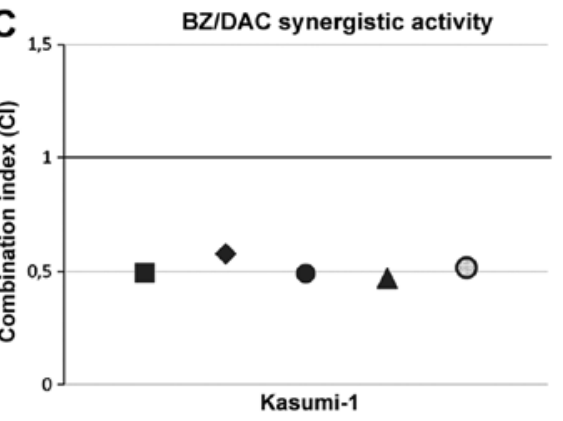

- BZ/DAC $10 \mathrm{nM}$

$\bullet B Z / D A C 50 \mathrm{nM}$

- BZ/DAC100 nM

$\triangle B Z / D A C 200 \mathrm{nM}$

OBZ/DAC $400 \mathrm{nM}$
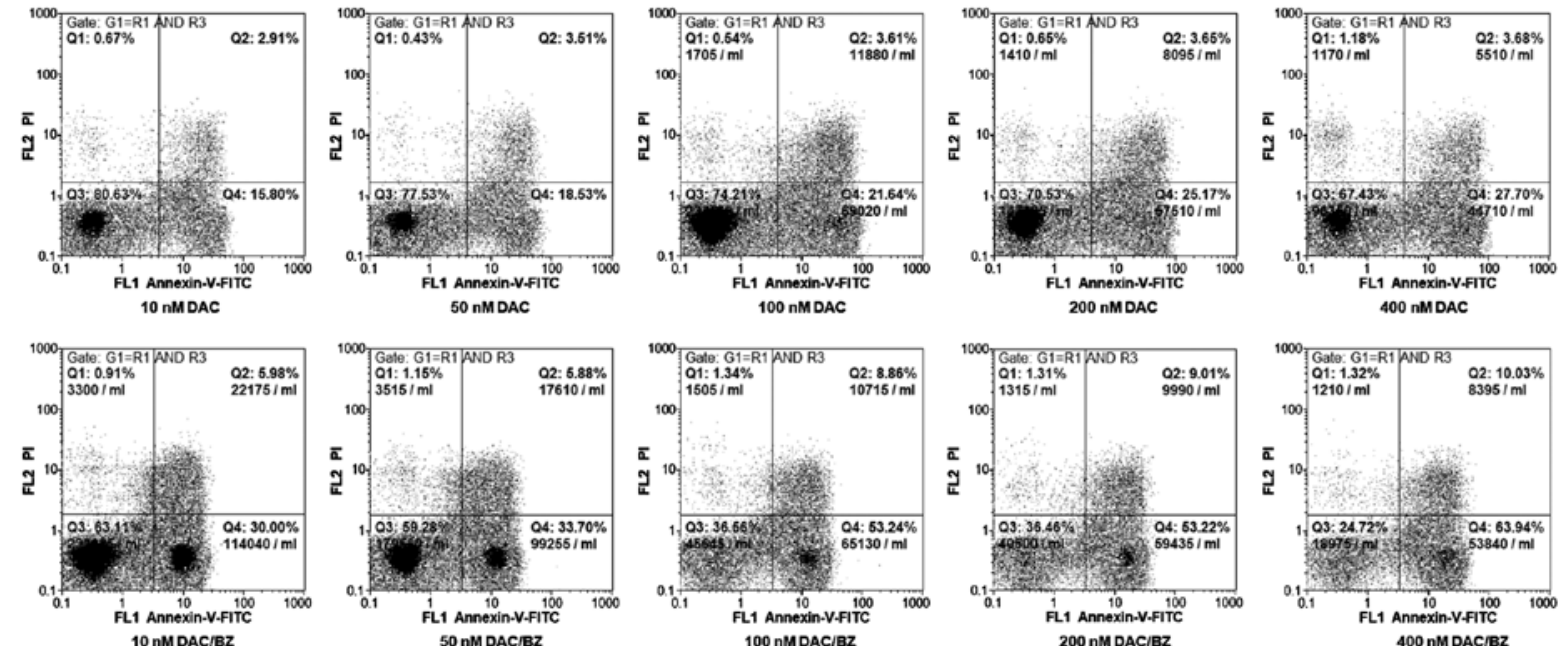

Figure 1. Apoptosis of the acute myeloid leukemia cell line Kasumi-1 following exposure to low doses of DAC and/or BZ. (A) Percentage of Annexin V-positive untreated cells and cells treated with 10,50,100,200 and $400 \mathrm{nM}$ DAC and/or $10 \mathrm{nM} \mathrm{BZ}$ for $24 \mathrm{~h}$. Comparisons between single DAC treatment and combination treatment with BZ, for all decitabine concentrations examined, are also presented. Values are expressed as the mean \pm standard deviation of three independent experiments. ${ }^{*} \mathrm{P}<0.05,{ }^{* *} \mathrm{P}<0.01$ as indicated or vs. untreated. (B) Representative dot plots of cells with Annexin V/PI staining for each drug treatment. Cells were gated on FSC/side scatter to include cells and on FSC area/FSC width to remove doublets. (C) The CI was calculated to determine drug interactions. Effects were defined as synergistic, additive and antagonistic when $\mathrm{CI}<1, \mathrm{CI}=1$ and $\mathrm{CI}>1$, respectively. BZ, bortezomib; DAC, Dacogen ${ }^{\circledR} / \mathrm{decitabine;} \mathrm{PI,}$ propidium iodide; q, quadrant; FSC, forward scatter; CI, combination index.

Furthermore, compared to single DAC treatments, the DAC/BZ combinations significantly increased apoptosis by $101.92,72$, 100.9, 113.12 and $96.63 \%(\mathrm{P}=0.009$ for $10 \mathrm{nM} \mathrm{DAC} ; \mathrm{P}=0.019$ for $50 \mathrm{nM}$ DAC; $\mathrm{P}<0.001$ for 100,200 and $400 \mathrm{nM}$ DAC; Fig. 1) and reduced the live cell population by $23.51,22.21$, $54.9,41$ and $49.81 \%$ for $10,50,100,200$ and $400 \mathrm{nM}$ of DAC in the DAC/BZ treatments, respectively $(\mathrm{P}=0.006$ and $\mathrm{P}=0.011$ for 10 and $50 \mathrm{nM}$ of DAC, respectively, and $\mathrm{P}<0.001$ for the remaining ones; data not shown). Most importantly, calculation of the CI revealed a synergistic effect for all low-dose DAC and BZ combinations $(\mathrm{CI}<1)$, with the 100 and $200 \mathrm{nM}$ DAC with BZ combinations exhibiting maximum synergy $(\mathrm{CI}=0.636$ and 0.631 , respectively; Fig. 1C). Therefore, these results indicated that $\mathrm{DAC} / \mathrm{BZ}$ combination treatment led to significant increases in the apoptotic rate of Kasumi-1 cells compared with untreated cells and single treatments.

DAC has a higher impact on the cell cycle in combination with $B Z$ and induces $G 0 / G 1$ - and G2/M-phase arrest in Kasumi-1 cells. After having demonstrated that the DAC/BZ combination leads to enhanced apoptosis in Kasumi-1 cells, its impact on the cell cycle was next investigated. The results indicated a significantly increased sensitivity of Kasumi-1 cells exposed to DAC/BZ combinations compared to those subjected to single treatments. More specifically, cells treated with 10, 50, 100 and $200 \mathrm{nM} \mathrm{DAC/BZ}$ appeared with a statistically significant increase in the $\mathrm{G} 0 / \mathrm{G} 1$ population, compared to single treatment, by $11.84 \%(\mathrm{P}<0.001)$, 

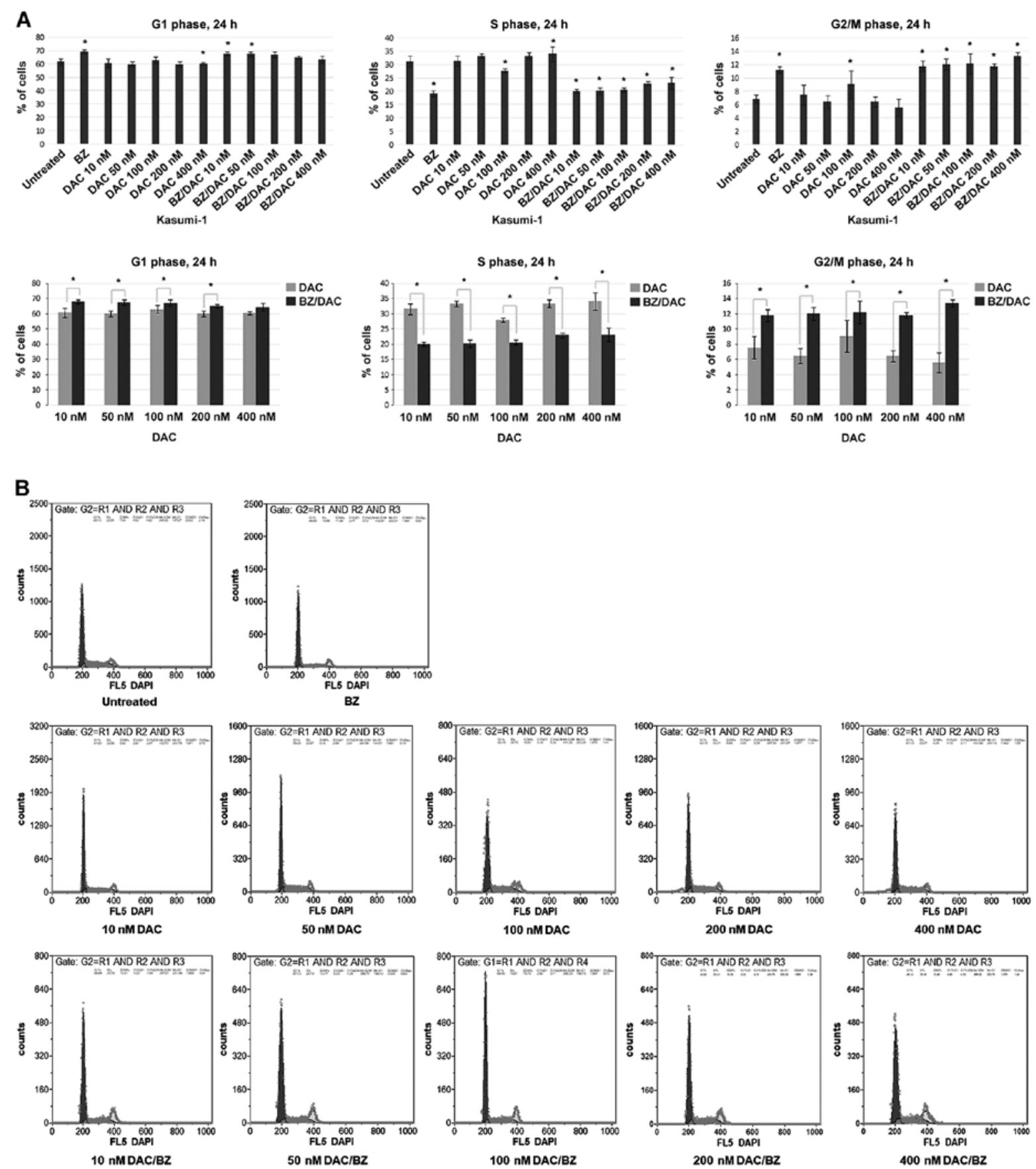

Figure 2. Effect of low doses of DAC and/or BZ on cell cycle progression in Kasumi-1 cells. (A) Kasumi-1 cells were treated with low doses of DAC (10, 50, 100,200 and $400 \mathrm{nM}$ ) and/or $10 \mathrm{nM} \mathrm{BZ}$ for $24 \mathrm{~h}$. The cell-cycle distribution was evaluated using flow cytometry. Bars represent the percentages of cells in G0/G1, S and G2/M phases and values are expressed as the mean \pm standard deviation of three independent experiments. Comparisons between single and combination treatments are also provided. (B) Representative cell cycle profiles determined by flow cytometry. Cells were gated on FSC/side scatter to include cells and on FSC area/FSC width to remove doublets. "P<0.05 as indicated or vs. untreated. BZ, bortezomib; DAC, Dacogen ${ }^{\circledR / d e c i t a b i n e ; ~ F S C, ~ f o r w a r d ~ s c a t t e r . ~}$

$12.55 \%(\mathrm{P}<0.001), 6.62 \%(\mathrm{P}=0.021)$ and $8.38 \%(\mathrm{P}=0.006)$, respectively. It should be noted that the $400 \mathrm{nM} \mathrm{DAC} / \mathrm{BZ}$ combination also produced an increase by $4.68 \%$ in the G0/G1 population compared to single treatment, although this was not statistically significant (Fig. 2). A significant decrease in the $\mathrm{S}$-phase population was observed after all DAC/BZ combination treatments tested compared to single ones, by $36.26,39.25,26,30.99$ and $30.8 \%$ from the lower to the higher DAC concentrations (10,50, 100, 200 and $400 \mathrm{nM})$, respectively $(\mathrm{P}<0.001$; Fig. 2$)$. Finally, the $\mathrm{G} 2 / \mathrm{M}$ population was increased by $56.35 \%(\mathrm{P}<0.001), 85.34 \%(\mathrm{P}<0.001)$,
34.29\% $(\mathrm{P}=0.02), 81.92 \%(\mathrm{P}<0.001)$ and $138.45 \%(\mathrm{P}<0.001)$, after treatment with $10,50,100,200$ and $400 \mathrm{nM}$ DAC/BZ respectively, compared with single treatment (Fig. 2). Thus, the $\mathrm{DAC} / \mathrm{BZ}$ treatments led to an increase in the proportion of cells in the G0/G1 and G2/M phases, while decreasing the $\mathrm{S}$-phase population, suggesting the induction of cell cycle arrest in $\mathrm{G} 0 / \mathrm{G} 1$ and $\mathrm{G} 2 / \mathrm{M}$ phases.

DAC-induced differentiation of Kasumi-1 cells is not further enhanced by BZ. The impact of low-dose DAC treatment on Kasumi-1 cell differentiation was then examined by 
A

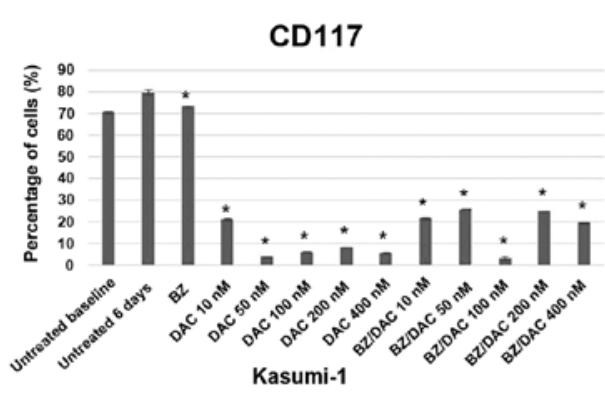

CD117

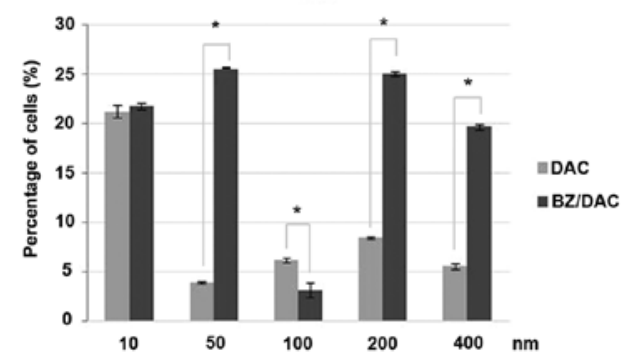

B

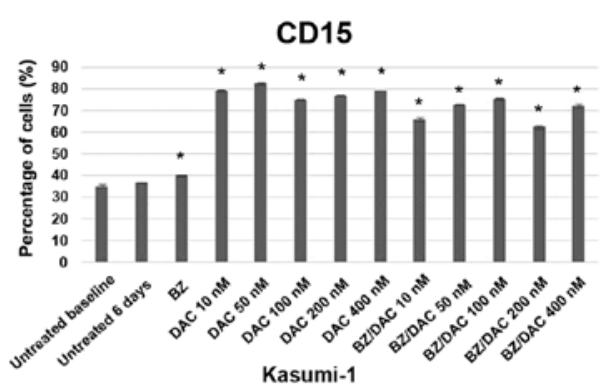

CD15

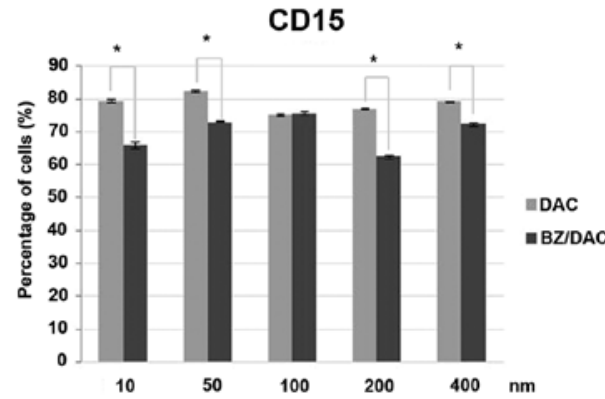

C
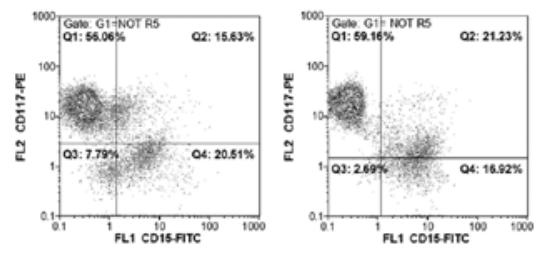

Untreated (baseline)

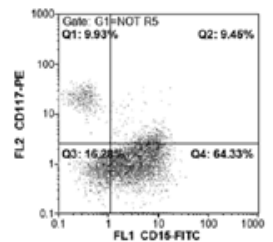

$10 \mathrm{nM} \mathrm{DAC}$

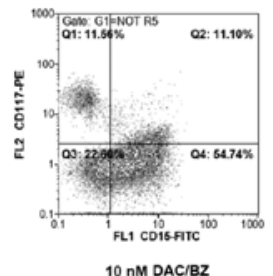

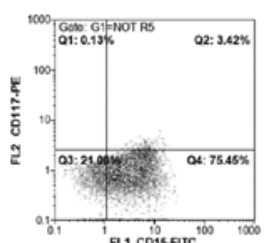

$50 \mathrm{nM}$ DAC

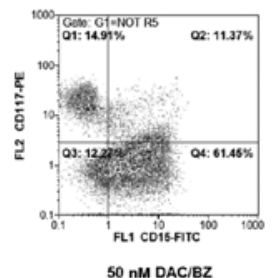

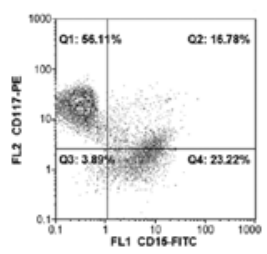

BZ
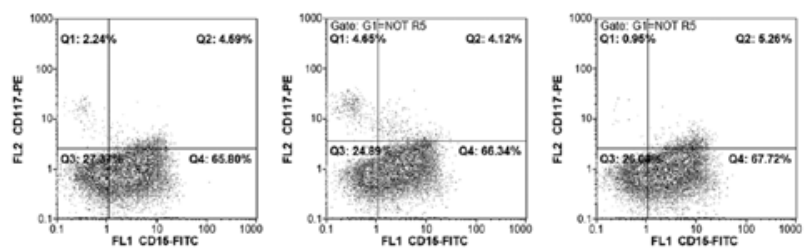

$100 \mathrm{nM}$ DAC
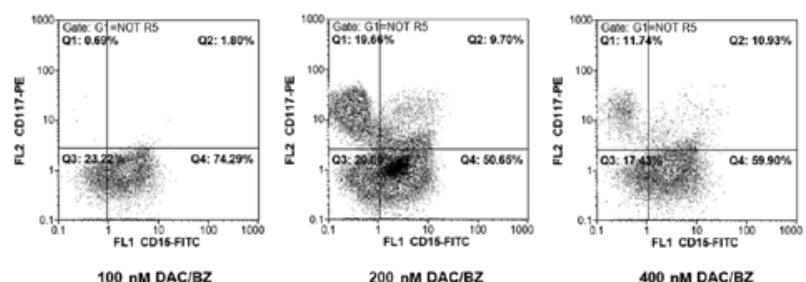

Figure 3. Effect of low-dose decitabine, bortezomib and their combination on differentiation surface markers on acute myeloid leukemia Kasumi-1 cells. Cells were exposed for 6 days to 10, 50, 100, 200 or $400 \mathrm{nM}$ DAC and/or $10 \mathrm{nM}$ of BZ, stained with antibodies against surface markers CD117 and CD15 and analyzed through flow cytometry. Bars in graphs represent the percentages of cells expressing (A) the myeloid progenitor surface antigen CD117 and (B) the monocytic surface antigen CD15. Values are expressed as the mean \pm standard deviation of three independent experiments. ${ }^{*}<0.05$ as indicated or vs. untreated (6 days). (C) Representative fluorescence-assisted cell sorting dot plots for each staining condition are presented. The expression of myeloid markers was evaluated in two parameter density plots by gating on $\mathrm{CD} 45^{+} \mathrm{dim} /$ side scatter low-medium blast cells. Q, quadrant; unt., untreated; BZ, bortezomib; DAC, Dacogen ${ }^{\circledR} /$ decitabine; PE, phycoerythrin.

measuring the cell surface levels of several myeloid, monocyte and granulocytic antigens (Fig. 3).

FACS analysis revealed decreased expression of the myeloid progenitor surface antigen CD117 after all treatments, single or combination, compared to 6 day-cultured untreated cells, which exhibited a CD117 expression ratio of $80.1 \pm 1.13 \%$. The percentages of CD117-expressing cells after the single DAC treatments were $21.25 \pm 0.63,3.9 \pm 0.14,6.15 \pm 0.21,8.45 \pm 0.07$ and $5.6 \pm 0.28 \%$, respectively, and $21.75 \pm 0.35,25.55 \pm 0.49$, $3.15 \pm 0.07,25.05 \pm 0.21$ and $19.7 \pm 0.28 \%$ for the $\mathrm{DAC} / \mathrm{BZ}$ combination treatments, respectively, from the lower to the higher DAC concentration ( $\mathrm{P}<0.001$ for all; Fig. 3A and $\mathrm{C}$ ). Of note, apart from the $100 \mathrm{nM}$ DAC/BZ combination, all other DAC/BZ combination treatments were significantly less 
effective in reducing CD117 expression on Kasumi-1 cells compared to the respective single DAC treatments.

Furthermore, FACS analysis revealed an increased expression of the granulocytic antigen CD15 after the treatments, compared to 6 day-cultured untreated cells, which exhibited a CD15 antigen expression of $36.7 \pm 0.28 \%$. The percentages of cells expressing CD15 from the lower to the higher DAC concentration $(10,50,100,200$ and $400 \mathrm{nM})$ were $79.35 \pm 0.49,82.55 \pm 0.35,75.15 \pm 0.35,77.05 \pm 0.21$ and $79.25 \pm 0.21 \% \quad(\mathrm{P}<0.001)$ for the single $\mathrm{DAC}$ treatments and $65.95 \pm 1.06,72.75 \pm 0.35,75.65 \pm 0.49,62.45 \pm 0.63$ and $72.35 \pm 0.63 \% \quad(\mathrm{P}<0.001)$ for the $\mathrm{DAC} / \mathrm{BZ}$ combination treatment, respectively (Fig. $3 \mathrm{~B}$ and $\mathrm{C}$ ). With the exception of $100 \mathrm{nM}$ DAC, all other single DAC treatments induced a higher expression of CD15 in Kasumi-1 cells compared to the respective $\mathrm{DAC} / \mathrm{BZ}$ combinations.

\section{Discussion}

Despite the increase in the survival rates of younger patients with AML over the past years, the 5-year survival rate of older patients ( $>60$ years old) still remains $<8 \%$ (8). Epigenetic alterations in leukemia constitute an attractive pharmacological target, mostly due to their reversible nature. DAC, as aforementioned, is an epigenetic modifying agent, used as first-line therapy for the treatment of high-risk MDS and AML, particularly for elderly patients or patients unfit for intensive chemotherapy (26-29). However, in DAC-treated patients, the estimated complete response rate is $30-40 \%$, while the majority of responders develop resistance within the following year (30-33).

Therefore, the present study aimed to examine the in vitro cellular effects of the epigenetic modifying agent DAC in combination with $\mathrm{BZ}$ - a proteasome inhibitor which also acts as an oxidative stress inducer - on apoptosis, cell cycle and cell differentiation in the human AML cell line Kasumi-1, carrying the $t(8 ; 21)$ and the KIT mutation N822, aiming to enhance the efficacy of DAC on AML cells.

The results suggested that, although both drugs were able to inhibit the growth of Kasumi-1 cells, their combination appeared more potent in suppressing cell proliferation. Indeed, the present results indicated that the addition of a low concentration of BZ $(10 \mathrm{nM})$ to low doses of DAC significantly enhanced apoptosis and decreased the live cell population of Kasumi-1 cells, with the 100 and $200 \mathrm{nM} \mathrm{DAC/BZ}$ combinations, which produced the maximum drug synergy according to the $\mathrm{CI}$ values, appearing to be the most successful ones. Furthermore, cell cycle profiling revealed that DAC/BZ treatment synergistically led to G0/G1- and G2/M-phase arrest, hence prohibiting cells to either synthesize DNA (S phase) or to complete mitosis.

Several studies have previously demonstrated that DNMTi cause tumor cell death by inducing apoptosis. DAC has also been reported to induce apoptosis in various leukemia cell lines (34-36). Recently, Zeng et al (37) investigated the effects of DAC treatment on the myeloid MDS cell line SKM-1 and investigated the role of FOXO3A, a potentially tumor-suppressive transcription factor, by silencing its expression prior to DAC treatment. They showed that the activation of FOXO3A gene is responsible for SKM-1 cell cycle arrest, apoptosis, and autophagy as well as for the DAC-induced differentiation of SKM-1 cells into monocytes.

Another study (38) demonstrated that apoptosis of human leukemic cells in response to treatment with DAC occurs through a mitochondria-mediated pathway that requires ROS generation upstream for disruption of the mitochondrial membrane potential, which leads to subsequent activation of caspases. Zhang et al (39) indicated that treatment of K562 leukemic cells with DAC led to a significant increase of G0/G1-and G2/M-phase populations, as well as a significant decrease in the S-phase population, which is in accordance with the present data on Kasumi-1 cells. Furthermore, they suggested that the methylation level of death receptor 4 (DR4) gene promoters gradually decreased, while the mRNA expression levels of DR4 genes gradually increased, thus suggesting that DAC is able to inhibit the proliferation of leukemia cells partly by terminating the methylation effect of DR4 gene promoters and restoring the mRNA expression of DR4 genes.

The present study indicated that BZ increased apoptosis and caused cell cycle alterations in the CBF AML cell line Kasumi-1 as compared to untreated cells, while it also displayed synergistic effects with DAC. These results are in line with the results of a previously published study, reporting that BZ manages to inhibit the growth of CBF AML by targeting the miR-29b/SP1/NF- $\kappa$ B(p65) complex-dependent overexpression of KIT (19). These observations are further supported by previous studies suggesting that BZ (either as a single agent or combined with other drugs, e.g., histone deacetylase inhibitors) inhibits the growth and induces apoptosis in leukemia cells, even with sensitivity or resistance to conventional chemotherapeutics (40). Relevant studies strongly suggest that proteasome inhibition should be considered as a therapy for leukemia $(41,42)$.

The present study reported a synergistic effect of DAC and $\mathrm{BZ}$ in the $\mathrm{CBF}$ AML Kasumi-1 leukemic cell line in terms of induction of apoptosis and inhibition of cell growth. Indeed, the combination of DAC and BZ has been previously studied in vitro in RPMI-8226 multiple myeloma cells and was indicated to enhance the apoptotic rate and induce G0/G1 arrest compared to single-agent therapy. Furthermore, it increased caspase- 3 and -9 activation and downregulated the expression levels of DNMT1 (43). Recently, another in vitro study by Jin et al (44) reported the synergistic antitumor efficacy of the combination of DAC and BZ in human multiple myeloma cell lines and revealed that DAC was able to synergistically enhance myeloma cell sensitivity to BZ by regulating Wnt/ $\beta$-catenin signaling. Specifically, the study proved that DAC demethylated and induced the re-expression of the Wnt antagonists secreted frizzled-related protein 3 and dickkopf WNT signaling inhibitor 1 , while it also reduced glycogen synthase kinase $3 \beta$ (Ser9) phosphorylation and decreased the BZ-mediated $\beta$-catenin accumulation in the nucleus. Thus, the transcription of cyclin D1, c-Myc and LEF/TCF was reduced, which synergistically inhibited cell proliferation, enhanced BZ-induced apoptosis and promoted BZ-induced cell cycle arrest in myeloma cells. Since the dysregulation of Wnt/ $\beta$-catenin signaling has been implicated in various hematological malignancies, including AML (45), such a mechanism may also be involved in the effects of DAC/BZ 
co-treatment of AML Kasumi-1 cells, further supporting the present observations regarding the synergistic activity of the two agents. Of note, a phase I clinical study by Blum et al (46) including 19 poor-risk patients AML reported promising clinical effects of the DAC/BZ combination and suggested that in AML, BZ acts through downregulation of fms-related receptor tyrosine kinase 3 due to upregulation of miR-29b, further validating the present observations in the Kasumi-1 cell line. Recently, a randomized phase 2 trial tested the efficacy of a 10-day DAC treatment with a 10-day DAC/BZ treatment, in previously untreated, newly diagnosed, elderly patients with AML (47). Although no clinical improvement was observed, responses were better than those in previous trials using 5-day DAC cycles. Currently, an ongoing phase I trial (registered at www.clinicaltrials.gov as \#NCT01861314) studied the side effects and the optimum dose of bortezomib and sorafenib to sylate when administered together with decitabine in patients with AML, although its results are yet to be announced.

Finally, the present results suggested that low doses of DAC induced monocytic and granulocytic differentiation of Kasumi-1 cells, in line with similar previous studies $(13,14,37)$. However, BZ did not appear to enhance the ability of DAC to induce the differentiation of Kasumi-1 cells and therefore, the synergistic activity of the two agents appears to rely on other mechanisms of action, including the induction of apoptosis and cell cycle alterations, possibly due to upstream events, such as DNA damage and oxidative stress production, that lead to cell growth inhibition.

In conclusion, the present study demonstrated that in human CBF AML Kasumi-1 cells, low doses of DAC in combination with BZ synergistically induce apoptosis and lead to G0/G1- and G2/M-phase arrest, hence prohibiting cells to either synthesize DNA (S phase) or complete mitosis. Although further in vitro investigation in other DAC-resistant AML cell lines and in vivo verifications are necessary, these results provide a strong rationale for the integration of combination treatment with DAC and BZ in AML therapy, followed by DAC alone, which will hopefully lead to better clinical responses and possibly partially overcome the frequently observed DAC resistance in patients with AML.

\section{Acknowledgements}

Not applicable.

\section{Funding}

The present study was supported by Janssen Cilag Pharmaceutical S.A.C.I, a Johnson \& Johnson, Company, under an Oncology \& Haematology Non-Clinical IIS Research Grant.

\section{Availability of data and materials}

All data generated and analyzed in the present study are available from the corresponding author on request.

\section{Authors' contributions}

VM conceived and designed the study, performed experiments, analyzed data and drafted the manuscript. AS performed part of the experiments, performed the statistical analysis of the data and contributed to drafting the manuscript. AB, EM, SP, $\mathrm{KG}$, EG and TT designed the study and drafted the manuscript. PF supervised and coordinated the study. VP conceived and supervised the study, participated in its design and coordination and reviewed the manuscript. All authors read and approved the final manuscript.

\section{Ethics approval and consent to participate}

Not applicable.

\section{Patient consent for publication}

Not applicable.

\section{Competing interests}

The present study was supported by Janssen Cilag Pharmaceutical S.A.C.I, a Johnson \& Johnson, Company, under an Oncology \& Haematology Non-Clinical IIS Research Grant, and included drug supply and financial support.

\section{References}

1. Torre LA, Bray F, Siegel RL, Ferlay J, Lortet-Tieulent J and Jemal A: Global cancer statistics, 2012. CA Cancer J Clin 65: 87-108, 2015.

2. Lapidot T, Sirard C, Vormoor J, Murdoch B, Hoang T, Caceres-Cortes J, Minden M, Paterson B, Caligiuri MA and Dick JE: A cell initiating human acute myeloid leukaemia after transplantation into SCID mice. Nature 367: 645-648, 1994

3. Bonnet D and Dick JE: Human acute myeloid leukemia is organized as a hierarchy that originates from a primitive hematopoietic cell. Nat Med 3: 730-737, 1997.

4. Konopleva MY and Jordan CT: Leukemia stem cells and microenvironment: Biology and therapeutic targeting. J Clin Oncol 29: 591-599, 2011.

5. Lane SW, Wang YJ, Lo Celso C, Ragu C, Bullinger L, Sykes SM, Ferraro F, Shterental S, Lin CP, Gilliland DG, et al: Differential niche and Wnt requirements during acute myeloid leukemia progression. Blood 118: 2849-2856, 2011

6. Valent P, Sadovnik I, Eisenwort G, Bauer K, Herrmann H, Gleixner KV, Schulenburg A, Rabitsch W, Sperr WR and Wolf D: Immunotherapy based targeting and elimination of leukemic stem cells in AML and CML. Int J Mol Sci 20: 4233, 2019.

7. Yates JW, Wallace HJ Jr, Ellison RR and Holland JF: Cytosine arabinoside (NSC-63878) and daunorubicin (NSC-83142) therapy in acute nonlymphocytic leukemia. Cancer Chemother Rep 57: 485-488, 1973.

8. Burnett A, Wetzler M and Löwenberg B: Therapeutic advances in acute myeloid leukemia. J Clin Oncol 29: 487-494, 2011.

9. BoseP,Vachhani Pand Cortes JE: Treatment of relapsed/refractory acute myeloid leukemia. Curr Treat Options Oncol 18: 17, 2017.

10. Kantarjian H, Oki Y, Garcia-Manero G, Huang X, O'Brien S, Cortes J, Faderl S, Bueso-Ramos C, Ravandi F, Estrov Z, et al: Results of a randomized study of 3 schedules of low-dose decitabine in higher-risk myelodysplastic syndrome and chronic myelomonocytic leukemia. Blood 109: 52-57, 2007.

11. Oki Y, Aoki E and Issa JP: Decitabine--bedside to bench. Crit Rev Oncol Hematol 61: 140-152, 2007.

12. Oki Y and Issa JP: Treatment options in advanced myelodysplastic syndrome, with emphasis on epigenetic therapy. Int $\mathrm{J}$ Hematol 86: 306-314, 2007.

13. Ding L, Qiu L, Zhang J and Guo B: Camptothecin-induced cell proliferation inhibition and apoptosis enhanced by DNA methyltransferase inhibitor, 5-aza-2'-deoxycytidine. Biol Pharm Bull 32: 1105-1108, 2009.

14. Turcan S, Fabius AW, Borodovsky A, Pedraza A, Brennan C, Huse J, Viale A, Riggins GJ and Chan TA: Efficient induction of differentiation and growth inhibition in IDH1 mutant glioma cells by the DNMT Inhibitor Decitabine. Oncotarget 4: 1729-1736, 2013. 
15. Fribley A, Zeng Q and Wang CY: Proteasome inhibitor PS-341 induces apoptosis through induction of endoplasmic reticulum stress-reactive oxygen species in head and neck squamous cell carcinoma cells. Mol Cell Biol 24: 9695-9704, 2004.

16. Fribley A and Wang CY: Proteasome inhibitor induces apoptosis through induction of endoplasmic reticulum stress. Cancer Biol Ther 5: 745-748, 2006.

17. Cortes J, Thomas D, Koller C, Giles F, Estey E, Faderl S, Garcia-Manero G, McConkey D, Ruiz SL, Guerciolini R, et al: Phase I study of bortezomib in refractory or relapsed acute leukemias. Clin Cancer Res 10: 3371-3376, 2004.

18. Attar EC, De Angelo DJ, Supko JG, D'Amato F, Zahrieh D, Sirulnik A, Wadleigh M, Ballen KK, McAfee S, Miller KB, et al: Phase I and pharmacokinetic study of bortezomib in combination with idarubicin and cytarabine in patients with acute myelogenous leukemia. Clin Cancer Res 14: 1446-1454, 2008.

19. Liu S, Liu Z, Xie Z, Pang J, Yu J, Lehmann E, Huynh L, Vukosavljevic T, Takeki M, Klisovic RB, et al: Bortezomib induces DNA hypomethylation and silenced gene transcription by interfering with Sp1/NF-kappaB-dependent DNA methyltransferase activity in acute myeloid leukemia. Blood 111: 2364-2373, 2008.

20. Liu S, Wu LC,Pang J, SanthanamR, Schwind S, Wu YZ,Hickey CJ, Yu J,BeckerH, Maharry K, et al: Sp1/NFkappaB/HDAC/miR-29b regulatory network in KIT-driven myeloid leukemia. Cancer Cell 17: 333-347, 2010.

21. Klco JM, Spencer DH, Lamprecht TL, Sarkaria SM, Wylie T, Magrini V, Hundal J, Walker J, Varghese N, Erdmann-Gilmore P, et al: Genomic impact of transient low-dose decitabine treatment on primary AML cells. Blood 121: 1633-1643, 2013.

22. Roccaro AM, Hideshima T, Raje N, Kumar S, Ishitsuka K, Yasui H, Shiraishi N, Ribatti D, Nico B, Vacca A, et al: Bortezomib mediates antiangiogenesis in multiple myeloma via direct and indirect effects on endothelial cells. Cancer Res 66 : 184-191, 2006.

23. Chou TC: Drug combination studies and their synergy quantification using the Chou-Talalay method. Cancer Res 70 : 440-446, 2010

24. Tomikoshi Y, Nomura M, Okudaira N, Sakagami H and Wakabayashi H: Enhancement of cytotoxicity of three apoptosis-inducing agents against human oral squamous cell carcinoma cell line by benzoxazinotropone. In Vivo 30: 645-650, 2016.

25. Iijima Y, Bandow K, Sano M, Hino S, Kaneko T, Horie N and Sakagami H: In vitro assessment of antitumor potential and combination effect of classical and molecular-targeted anticancer drugs. Anticancer Res 39: 6673-6684, 2019.

26. Jabbour E, Issa JP, Garcia-Manero G and Kantarjian H: Evolution of decitabine development: Accomplishments, ongoing investigations, and future strategies. Cancer 112: 2341-2351, 2008.

27. Erba HP: Finding the optimal combination therapy for the treatment of newly diagnosed AML in older patients unfit for intensive therapy. Leuk Res 39: 183-191, 2015.

28. Welch JS, Petti AA, Miller CA, Fronick CC, O'Laughlin M, Fulton RS, Wilson RK, Baty JD, Duncavage EJ, Tandon B, et al: TP53 and Decitabine in Acute Myeloid Leukemia and Myelodysplastic Syndromes. N Engl J Med 375: 2023-2036, 2016.

29. Tamamyan G, Kadia T, Ravandi F, Borthakur G, Cortes J, Jabbour E, Daver N, Ohanian M, Kantarjian H and Konopleva M: Frontline treatment of acute myeloid leukemia in adults. Crit Rev Oncol Hematol 110: 20-34, 2017.

30. Blum W, Garzon R, Klisovic RB, Schwind S, Walker A, Geyer S, Liu S, Havelange V, Becker H, Schaaf L, et al: Clinical response and miR-29b predictive significance in older AML patients treated with a 10-day schedule of decitabine. Proc Natl Acad Sci USA 107: 7473-7478, 2010 .

31. Ritchie EK, Feldman EJ, Christos PJ, Rohan SD, Lagassa CB, Ippoliti C, Scandura JM, Carlson K and Roboz GJ: Decitabine in patients with newly diagnosed and relapsed acute myeloid leukemia. Leuk Lymphoma 54: 2003-2007, 2013.
32. Bhatnagar B, Duong VH, Gourdin TS, Tidwell ML, Chen C, Ning Y,Emadi A, Sausville EA and Baer MR: Ten-day decitabine as initial therapy for newly diagnosed patients with acute myeloid leukemia unfit for intensive chemotherapy. Leuk Lymphoma 55: 1533-1537, 2014.

33. Khan N, Hantel A, Knoebel RW, Artz A, Larson RA, Godley LA, Thirman MJ, Liu H, Churpek JE, King D, et al: Efficacy of single-agent decitabine in relapsed and refractory acute myeloid leukemia. Leuk Lymphoma 58: 1-7, 2017.

34. Stresemann C, Bokelmann I, Mahlknecht U and Lyko F: Azacytidine causes complex DNA methylation responses in myeloid leukemia. Mol Cancer Ther 7: 2998-3005, 2008.

35. Valdez BC, Li Y, Murray D, Corn P, Champlin RE and Andersson BS: 5-Aza-2'-deoxycytidine sensitizes busulfan-resistant myeloid leukemia cells by regulating expression of genes involved in cell cycle checkpoint and apoptosis. Leuk Res 34: 364-372, 2010.

36. Tsujioka T, Yokoi A, Uesugi M, Kishimoto M, Tochigi A, Suemori S, Tohyama Y and Tohyama K: Effects of DNA methyltransferase inhibitors (DNMTIs) on MDS-derived cell lines. Exp Hematol 41: 189-197, 2013.

37. Zeng W, Dai H, Yan M, Cai X, Luo H, Ke M and Liu Z: Decitabine-Induced Changes in Human Myelodysplastic Syndrome Cell Line SKM-1 Are Mediated by FOXO3A Activation. J Immunol Res 2017: 4302320, 2017.

38. Shin DY, Park YS, Yang K, Kim GY, Kim WJ, Han MH, Kang HS and Choi YH: Decitabine, a DNA methyltransferase inhibitor, induces apoptosis in human leukemia cells through intracellular reactive oxygen species generation. Int J Oncol 41: 910-918, 2012.

39. Zhang W, Chen Y, Pei X, Zang Y and Han S: Effects of Decitabine on the proliferation of K562 cells and the expression of DR4 gene. Saudi J Biol Sci 25: 242-247, 2018.

40. Csizmar CM, Kim DH and Sachs Z: The role of the proteasome in AML. Blood Cancer J 6: e503, 2016.

41. Vink J, Cloos J and Kaspers GJ: Proteasome inhibition as novel treatment strategy in leukaemia. Br J Haematol 134: 253-262, 2006.

42. McCloskey SM, McMullin MF, Walker B and Irvine AE: The therapeutic potential of the proteasome in leukaemia. Hematol Oncol 26: 73-81, 2008.

43. Cao Y, Qiu GQ, Wu HQ, Wang ZL, Lin Y, Wu W, Xie XB and Gu WY: Decitabine enhances bortezomib treatment in RPMI 8226 multiple myeloma cells. Mol Med Rep 14: 3469-3475, 2016.

44. Jin Y, Xu L, Wu X, Feng J, Shu M, Gu H, Gao G, Zhang J, Dong B and Chen X: Synergistic efficacy of the demethylation agent decitabine in combination with the protease inhibitor bortezomib for treating multiple myeloma through the Wnt $/ \beta$-catenin pathway. Oncol Res 27: 729-737, 2019.

45. Grainger S, Traver D and Willert K: Wnt signaling in hematological malignancies. Prog Mol Biol Transl Sci 153: 321-341, 2018.

46. Blum W, Schwind S, Tarighat SS, Geyer S, Eisfeld AK, Whitman S, Walker A, Klisovic R, Byrd JC, Santhanam R, et al: Clinical and pharmacodynamic activity of bortezomib and decitabine in acute myeloid leukemia. Blood 119: 6025-6031, 2012.

47. Roboz GJ, Mandrekar SJ, Desai P, Laumann K, Walker AR, Wang ES, Kolitz JE, Powell BL, Attar EC, Stock W, et al: Randomized trial of 10 days of decitabine \pm bortezomib in untreated older patients with AML: CALGB 11002 (Alliance). Blood Adv 2: 3608-3617, 2018.

This work is licensed under a Creative Commons Attribution-NonCommercial-NoDerivatives 4.0 International (CC BY-NC-ND 4.0) License. 